\title{
Sinirsel Bulanık Ağlarla Asenkron Motorların Algılayıcısız Denetimi
}

\author{
Cafer BAL ${ }^{1 *}$, Muammer GÖKBULUT ${ }^{2}$, Fikret ATA ${ }^{3}$ \\ ${ }^{1}$ Fırat Üniversitesi, Teknoloji Fakültesi, Mekatronik Mühendisliği Bölümü, Elazığ \\ ${ }^{2}$ Fırat Üniversitesi, Teknoloji Fakültesi, Elektrik-Elektronik Mühendisliği Bölümü, Elazığ \\ ${ }^{3}$ Bingöl Üniversitesi, Mühendislik Fakültesi, Elektrik-Elektronik Mühendisliği Bölümü, Bingöl \\ cbal@firat.edu.tr
}

(Geliș/Received:05/03/2020;

Kabul/Accepted: 30/07/2020)

\begin{abstract}
Öz: Bu çalışmada, akım gözlemleyici olarak kullanılan sinirsel bulanık ağlarla asenkron motorun (ASM) algılayıcısız hız denetimi gerçekleştirilmiştir. Önerilen sinirsel bulanık akım gözlemleyici, akı ve hız tahmini yapmak yerine doğrudan denetleyici olarak kullanılmıştır. Sinirsel bulanık akım gözlemleyici, deneysel verilerle gerçek zamanlı eğitilmiş ve eğitilmiş ağ yapısı kullanılarak farklı çalışma koşullarında denetim sisteminin başarımı test edilmiştir. Sinirsel bulanık ağın eğitimi ve denetim algoritması MATLAB/Simulink ortamında programlanmış ve DSPACE-DS1104 sayısal işaret işlemcisi (Sİi) ile gerçekleştirilmiştir. Deneysel sonuçlar, değişkenlere gerçek zamanlı erişimi sağlayabilen Control Desk Developer yazılımı kullanılarak oluşturulan bir arayüzden elde edilmiştir. Farklı hız ve yük koşullarında elde edilen benzetim ve deneysel sonuçlarla, önerilen algılayıcısız denetim yönteminin başarımı gösterilmiştir.
\end{abstract}

Anahtar kelimeler: Asenkron motor, sinirsel bulanık ağlar, algılayıcısız denetim.

\section{Speed Sensorless Control of Induction Motor Using Fuzzy-Neural Networks}

\begin{abstract}
In this paper, a fuzzy neural network current observer is proposed for the sensorless speed control of induction motor. The proposed neural fuzzy current observer is used as a direct controller rather than flux and speed estimation. Fuzzy neural network current observer is trained online with the experimental data. Performance of the control system including the trained fuzzy neural network current observer is tested for various operating conditions of the motor. Training algorithm of fuzzy neural network and the control algorithm are prepared at the MATLAB/Simulink environment and it is implemented using the digital signal processor (DSP) dSPACE-DS1104. Experimental results are acquired from the developed interface using Control Desk Developer software which allows online access to the variables. The performance of proposed sensorless control method is verified with the simulation and experimental results under different speed and load conditions.
\end{abstract}

Keywords: Induction motor, fuzzy neural network, sensorless control.

\section{Giriş}

Güç elektroniği ve mikroişlemci teknolojilerindeki gelişmeler, ASM'lerin vektör denetimi veya doğrudan tork denetimi gibi etkin denetim algoritmalarının geliştirilmesine yol açmıştır. Vektör denetim yöntemi, motorun ak1 ve tork değişkenlerinin birbirinden bağımsız olarak denetlenmesine imkân vermektedir. ASM sürücülerinin vektör denetiminde doğru bir hız algılaması gereklidir ve ASM'ler doğrudan hızı ölçmek amacı ile kullanılabilecek hiçbir elektriksel stator değişkenine sahip değildir. Bu nedenle denetim algoritmalarında, rotor akı açısını tahmin etmek için bir hız veya konum algılayıcısına ihtiyaç duyulur. Mekanik kodlayıcılar genellikle motorun kendisinden daha az dayanıklı ve daha pahalıdır. Hız algılayıcısı bütün sürücü güvenirliğini bozar, tamir veya bakımının zor olabileceği belirli ortamlarda kullanımını sınırlar. Bu sınırlamalar, algılayıcısız hız denetimi olarak bilinen ve ölçülebilen elektriksel veya mekaniksel büyüklüklerle dolaylı olarak akıdan motor hızını ya da konumunu gözlemlemeye amaçlayan çalışmalara yol açmıştır. Genellikle bu gözlemleyiciler, fiziksel sistem ile aynı girişleri alan ve ölçülen durumları izleyebilen, denetlenen sistemin gerçek zamanlı modelleridir. Algılayıcısız ASM sürücüleri için literatürde önerilen üç temel gözlemleyici algoritması vardır: Genişletilmiş Kalman Filtre (GKF) ile rotor hız ve durum tahmincileri, Model Referans Uyarlamalı Sistem (MRUS) ve uyarlamalı akı gözlemleyiciler.

Genişletilmiş kalman filtreler model belirsizlikleri ve gürültülü koşullar altında yüksek doğrulukla durum tahmini yapmasına karşın fazla hesaplama zamanı gerektirir. Ayrıca düşük hızlarda sürekli durum hatası meydana gelirken, parametre değişimleri gözlemleyici başarımını azaltır [1-4]. MRUS ve uyarlamalı akı gözlemleyici algoritmaları algılayıcısız ASM uygulamalarında geniş ölçüde kullanılmaktadır [5-7]. Gerçek zamanda stator ve rotor dirençlerinin tahmininde de kullanılabilmesi bu gözlemleyicilerin avantajıdır [8,9]. MRUS yönteminin gerçeklenmesi basit ve daima kararlı iken, düşük hız aralığındaki başarımı ve yapısındaki açık integrasyon kararsızlığa neden olabileceği için verimsizdir [1]. Kayma kip (KK) tekniği ile gerçekleştirilen kayma kipli

\footnotetext{
* Sorumlu yazar: cbal@firat.edu.tr. Yazarların ORCID Numaras1: ${ }^{10000-0002-1199-2637, ~}{ }^{20000-0003-1870-1772, ~}{ }^{30000-0003-1100-6179}$
} 
gözlemleyicilerin (KKG) en büyük avantajı motorun parametre değişimlerine ve belirsiz yük değişimlerine duyarlılığının daha az olmasıdır [10]. Yüksek frekanslı anahtarlamadan kaynaklanan çatırdama (titreşim) ise KK'nin büyük bir dezavantajını oluşturur [11].

ASM'nin algılayıcısız vektör denetiminde, farklı denetleyicilerle birlikte yapay sinir ağları (YSA) motorun hız, akı, akım ve moment gibi büyüklüklerinin gözlemlenmesinde veya motor parametrelerinin tahmininde ve MRUS yapılarında yaygın olarak incelenmiştir [12-23]. [12-16]'te MRUS yönteminde yer alan ASM akım denklemleri yerine doğrusal hücreli YSA kullanılmış ve referans model çıkışına göre geriye yayılım algoritması ile gerçek zamanlı olarak eğitilen YSA'nın uygun ağırlığı motor hızı olarak kullanılmıştır. [20]'da dönen referans çatıda, gerçek zamanda eğitilen doğrusal hücreli YSA'nın uygun bir ağıllığı hıza bağımlıdır. Böylelikle YSA çıkışı referans akıya yakınsadı̆̆ında ilgili ağırlık motor hızına yakınsayacağı varsayılmışıtır. [21]'de, motorun rotor akılarını ve hızını ayrı ayrı tanılayan iki YSA kullanılmıştır. İlk YSA yapısı ile modele göre rotor akıları öğretilmiş; daha sonra bu YSA çıkışı ve motor akımları kullanılarak ikinci YSA motor hızını tanılamak üzere eğitilmiştir. Eğitim sonunda motorun algılayıcısız denetiminde kullanılmıștır. [22]'de YSA sadece MRUS ile algılayıcısız denetim yapısında yer alan referans modeldeki stator direncinin uyarlanması amacıyla kullanılmıştır. YSA'nın kullanıldığ1 yöntemlerin hemen hepsinde, kullanılan referans model sabit parametreli motor dinamik denklemlerinden oluşturulmuştur. Bu nedenle motor çalışma koşullarının etkisi ile parametre değişimlerine açık iken, model parametrelerinin motor parametre değişimlerinden etkilenmesi söz konusu değildir. Bu nedenle, motor parametreleri değiştiğinde, model artık farklı parametrelere sahip bir motorun referansı olacaktır. Yani referans modelin ürettiği büyüklükler motorun gerçek nicelikleri olmayacaktır. Bu durumda, YSA her ne kadar referans modeli başarılı bir şekilde takip etse de, referans model çıkışları gerçek motor sistemi büyüklüklerini yansıtmadığından gözlemlenen hız gerçek motor hızından farklı olacaktır.

Sinirsel bulanık ağın (SBA), ASM'nin algılayıcısız denetiminde gözlemleyici olarak fazla bir kullanımına rastlanmamıştır. [24]'de iki adet SBA kullanılarak ASM algılayıcısız denetimi için benzetim çalışması gerçekleştirilmiştir. $\mathrm{Bu}$ çalışmada, [25] ile gerçekleştirilen YSA ile denetim yapısının aynısı SBA ile gerçekleştirilmiştir. Bu çalışmalarda YSA ve SBA yapıları birleştirilerek motor hızını öğrenecek şekilde eğitilmiş ve daha sonra hız gözlemleyici olarak algılayıcısız denetim sisteminde kullanılmışıır. Böyle bir yapı için, motor parametre değişimlerini karşılayabilecek tek güvence YSA ve SBA yapılarının kendi dayanıklılığı ile sınırlanır. Yani, bu gözlemleyici modeller kullanıldıkları esnada uyarlama olmadığından, sabit parametreli doğrusal olmayan bir model olarak işlev görecektir.

$\mathrm{Bu}$ çalışmada, akım gözlemleyici olarak kullanılan sinirsel bulanık ağlarla asenkron motorun algılayıcısız hız denetimi gerçekleștirilmiștir. Önerilen sinirsel bulanık akım gözlemleyici, akı ve hız tahmini yapmak yerine doğrudan denetleyici olarak kullanıldığından farklı bir yaklaşım sunmaktadır. Böylece motor parametrelerinden bağımsız ve SBA tabanlı bir akım gözlemleyici modeli ile algılayıcısız denetim yapısı geliştirilmiştir. Sinirsel bulanık akım gözlemleyici, deneysel verilerle gerçek zamanlı eğitilmiştir. Eğitilmiş ağ yapısı kullanılarak farklı çalışma koşullarında denetim sisteminin başarımı test edilmiştir. Sinirsel bulanık ağın eğitimi ve denetim algoritması MATLAB/Simulink ortamında programlanmış ve dSPACE-DS1104 Siİ ile gerçekleștirilmiştir. Deneysel sonuçlar, değişkenlere gerçek zamanlı erişimi sağlayabilen Control Desk Developer yazılımı kullanılarak oluşturulan bir arayüzden elde edilmiştir. Farklı hız ve yük koşullarında elde edilen benzetim ve deneysel sonuçlarla, önerilen algılayıcısız denetim yönteminin başarımı gösterilmiştir.

\section{Akım Gözlemleyicili Algılayıcısız Denetim Yöntemi}

Bir asenkron motorun senkron hızla dönen referans çatıdaki matematiksel modeli Şekil 1'de görüldüğü gibi, giriș değişkenleri stator gerilimleri, çıkış değişkenleri ise stator akımları ve motor hızı olmak üzere çok girişli-çok çıkışlı bir sistemdir. Şekil 2'de, motor hızı, sistem girişi olarak alınmak suretiyle giriş ve çıkış değişkenleri yeniden oluşturulan akım gözlemleyici modeli verilmiştir. Bu iki modelden, stator gerilimleri aynı olmak şartıyla, motor ve modelin stator akımları aynı olmaya zorlanırsa, motor hızı da model hızına (aynı zamanda referans) yaklaşmaya zorlanacaktır [26, 27]. Yani $v_{d s}^{s}=v_{d s m}^{s}$ ve $v_{q s}^{s}=v_{q s m}^{s}$ olmas1 durumunda, $i_{d s}^{s}=i_{d s m}^{s}$ ve $i_{q s}^{s}=i_{q s m}^{s}$ olursa, o zaman $\omega_{r}=\omega_{r m}$ olacaktır. Dolayısıyla akım gözlemleyicili algılayıcısız denetim yöntemi, akı ve hız tahminine gerek duymadığından mevcut yöntemlerden farklı bir yaklaşım sunmaktadır. 


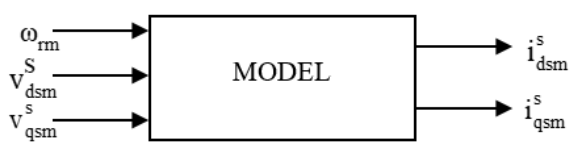

(a)

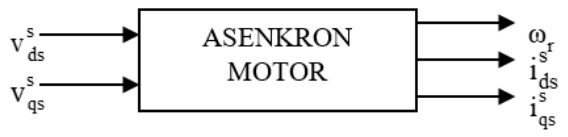

(b)

Şekil 1. Model giriş çıkışları diyagramı, a) ASM akım gözlemleyici modeli b) ASM modeli

Akım gözlemleyicili algılayıcısız denetim yöntemi, asenkron motorun senkron hızla dönen referans çatıdaki matematiksel modeli kullanılarak açıklanabilir. Senkron referans çatı motor denklemleri ve elektromanyetik moment ifadeleri aşağıdaki gibi verilebilir.

$$
\begin{aligned}
& v_{d s}^{e}=R_{s} i_{d s}^{e}+\frac{d \psi_{d s}^{e}}{d t}-\omega_{e} \psi_{q s}^{e} \\
& v_{q s}^{e}=R_{s} i_{q s}^{e}+\frac{d \psi_{q s}^{e}}{d t}-\omega_{e} \psi_{d s}^{e} \\
& 0=R_{r} i_{d r}^{e}+\frac{d \psi_{d r}^{e}}{d t}-\left(\omega_{e}-\omega_{r}\right) \psi_{q r}^{e} \\
& 0=R_{r} i_{q r}^{e}+\frac{d \psi_{q r}^{e}}{d t}+\left(\omega_{e}-\omega_{r}\right) \psi_{d r}^{e} \\
& T_{e}=\frac{3}{2} \frac{P}{2} \frac{L_{m}}{L_{r}}\left(i_{q s}^{e} \psi_{d r}^{e}-i_{d s}^{e} \psi_{q r}^{e}\right)
\end{aligned}
$$

Burada $\omega_{\mathrm{e}}$ senkron hız, $\omega_{\mathrm{r}}$ rotor hızıdır. Stator ve rotor akı denklemleri aşağıdaki gibi verilebilir.

$$
\begin{aligned}
& \psi_{d s}^{e}=L_{s} i_{d s}^{e}+L_{m} i_{d r}^{e} \\
& \psi_{q s}^{e}=L_{s} i_{q s}^{e}+L_{m} i_{q r}^{e} \\
& \psi_{d r}^{e}=L_{r} i_{d r}^{e}+L_{m} i_{d s}^{e} \\
& \psi_{\mathrm{qr}}^{\mathrm{e}}=\mathrm{L}_{\mathrm{r}} \mathrm{i}_{\mathrm{qr}}^{\mathrm{e}}+\mathrm{L}_{\mathrm{m}} \mathrm{i}_{\mathrm{qs}}^{\mathrm{e}}
\end{aligned}
$$

Denklem 8 ve 9'dan rotor akımları,

$$
\begin{aligned}
& i_{d r}^{e}=\frac{1}{L_{r}}\left(\psi_{d r}^{e}-L_{m} i_{d s}^{e}\right) \\
& \mathrm{i}_{\mathrm{qr}}^{\mathrm{e}}=\frac{1}{\mathrm{~L}_{\mathrm{r}}}\left(\psi_{\mathrm{qr}}^{\mathrm{e}}-\mathrm{L}_{\mathrm{m}} \mathrm{i}_{\mathrm{qs}}^{\mathrm{e}}\right)
\end{aligned}
$$

elde edilerek Denklem 3 ve 4'de yerine yazılırsa,

$$
\begin{gathered}
\frac{d \psi_{d r}^{e}}{d t}+\frac{R_{r}}{L_{r}} \psi_{d r}^{e}-\frac{L_{m}}{L_{r}} R_{r} i_{d s}^{e}-\omega_{s l} \psi_{q r}^{e}=0 \\
\frac{d \psi_{q r}^{e}}{d t}+\frac{R_{r}}{L_{r}} \psi_{q r}^{e}-\frac{L_{m}}{L_{r}} R_{r} i_{q s}^{e}-\omega_{s l} \psi_{d r}^{e}=0
\end{gathered}
$$

rotor gerilim denklemleri elde edilir. Burada $\omega_{\text {sl }}$ kayma hızıdır. Eğer vektör denetimi ile, q eksen akısı sıfır ( $\left.\psi_{\mathrm{qr}}^{\mathrm{e}}=0\right)$ yapılabilir, ve d eksen akısı sabit $\left(\frac{d \psi_{d r}^{e}}{d t}=0\right)$ tutulabilirse, Denklem 5'e göre, elektromanyetik moment sadece stator akımlarının q eksen akımı ile denetlenebilir. 


$$
T_{e}=\frac{3}{2} \frac{P}{2} \frac{L_{m}}{L_{r}} \psi_{d r}^{e} i_{q s}^{e}
$$

ve ayrıca bu akılar, Denklem 3 ve 11 - 13 de yerine yazılırsa,

$$
\begin{aligned}
& i_{d r}^{e}=0 \\
& i_{q r}^{e}=-\frac{L_{m}}{L_{r}} i_{q s}^{e} \\
& \psi_{d r}^{e}=L_{m} i_{d s}^{e} \\
& \omega_{s l}=\frac{L_{m}}{T_{r}} \frac{i_{q s}^{e}}{\psi_{d r}^{e}}=\frac{1}{T_{r}} \frac{i_{q s}^{e}}{i_{d s}^{e}}
\end{aligned}
$$

elde edilir. Buradan Denklem 6 - 7 ve Denklem 15 -8, Denklem 1 ve 2'de yerine yazılırsa motorun ve model stator gerilim denklemleri,

$$
\begin{aligned}
& v_{d s}^{e}=R_{s} i_{d s}^{e}-\omega_{e} \sigma L_{s} i_{q s}^{e} \\
& v_{d s m}^{e}=R_{s} i_{d s m}^{e}-\omega_{e m} \sigma L_{s} i_{q s m}^{e} \\
& v_{q s}^{e}=R_{s} i_{q s}^{e}+\sigma L_{s} \frac{d i_{q s}^{e}}{d t}+\omega_{e} L_{s} i_{d s}^{e}=R_{s} i_{q s}^{e}+\sigma L_{s} \frac{d i_{q s}^{e}}{d t}+L_{s} i_{d s}^{e}\left(\omega_{r}+\frac{1}{T_{r}} \frac{i_{q s}^{e}}{i_{d s}^{e}}\right) \\
& v_{q s m}^{e}=R_{s} i_{q s m}^{e}+\sigma L_{s} \frac{d i_{q s m}^{e}}{d t}+\omega_{e} L_{s} i_{d s m}^{e}=R_{s} i_{q s m}^{e}+\sigma L_{s} \frac{d i_{q s m}^{e}}{d t}+L_{s} i_{d s m}^{e}\left(\omega_{r}+\frac{1}{T_{r}} \frac{i_{q s m}^{e}}{i_{d s m}^{e}}\right)
\end{aligned}
$$

olarak bulunur. Burada motor ve modele aynı gerilimler uygulanırsa, yani $v_{d s}^{e}=v_{d s m}^{e}$ ve $v_{q s}^{e}=v_{q s m}^{e}$ olursa Denklem $19-22$ den,

$$
\begin{aligned}
& \sigma L_{s}\left(\omega_{e} i_{q s}^{e}-\omega_{e m} i_{q s m}^{e}\right)=R_{s}\left(i_{d s}^{e}-i_{d s m}^{e}\right) \\
& L_{s}\left(\omega_{e} i_{d s m}^{e}-\omega_{e} i_{d s}^{e}\right)=R_{s}\left(i_{q s}^{e}-i_{q s m}^{e}\right)+\sigma L_{s} \frac{d}{d t}\left(i_{q s}^{e}-i_{q s m}^{e}\right) \\
& L_{s}\left(\omega_{r m} i_{d s m}^{e}-\omega_{r} i_{d s}^{e}\right)=\left(R_{s}+\frac{L_{s}}{T_{r}}\right)\left(i_{q s}^{e}-i_{q s m}^{e}\right)+\sigma L_{s} \frac{d}{d t}\left(i_{q s}^{e}-i_{q s m}^{e}\right)
\end{aligned}
$$

elde edilir. Denklem 23 - 25'den görüldüğü gibi, $i_{d s}=i_{d s m}$ ve $i_{q s}=i_{q s m}$ olursa o zaman $\omega_{e}=\omega_{e m}$ ve olur. Bu nedenle modelin ve motorun moment üreten akımları ve akı üreten akımları aynı olacak şekilde denetlenirse motor hızı ile model hızı, yani referans hız ile aynı olmaya zorlanır. Ayrıca Denklem 23 ve 24 'ten görüldüğü gibi akı üreten akımın denetimi gerekmez. Çünkü moment üreten iki akım aynı olacak şekilde denetlenirse, akı üreten akımlarında aynı olması gerekir. Denklem $18^{\text {'den, }}$

$$
\omega_{r}+\frac{1}{T_{r}} \frac{i_{q s}^{e}}{i_{d s}^{e}}=\omega_{r m}+\frac{1}{T_{r}} \frac{i_{q s m}^{e}}{i_{d s m}^{e}}
$$

olmas1 gerekir. Buna göre Denklem 23 ve Denklem 26'dan, eğer $\omega_{r}>\omega_{r m}$ olursa o zaman, $i_{q s}<i_{q s m}$ ve eğer $\omega_{r}<\omega_{r m}$ olursa o zaman $i_{q s}>i_{q s m}$ olması gerektiği bulunabilir.

Akım gözlemleyicili algılayıcısız hız denetim sisteminin blok diyagramı Şekil 2'de verilmiştir. Model duran referans çatıda seçildiğinden model bloğu içerisinde akımların senkron referans çatıya dönüşümü de yer almaktadir. 


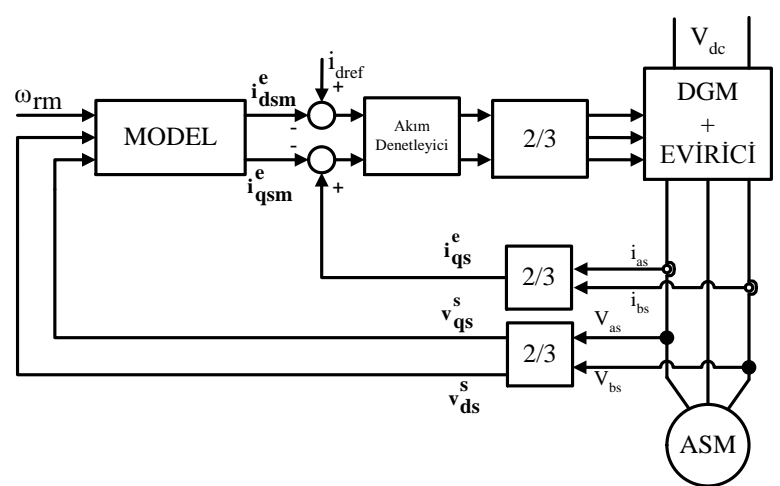

Şekil 2. ASM’un akım gözlemleyicili algılayıcısız denetimi

\section{SBA ile Akım Gözlemleyicili Algılayıcısız Denetim}

Denetim yapısı Şekil 2 de verilen akım gözlemleyicili algılayıcısız denetimin başarısı, asenkron motorun dinamik modeli kullanılarak oluşturulan akım gözlemleyici modelin, asenkron motoru doğru olarak temsil etmesine bağlıdır. Dolayısıyla, oluşturulan modelin parametreleri, motor parametreleri ölçülerek belirlenmelidir. Motorun akım gözlemleyici modeli olarak adlandırılan bu sabit parametreli model, parametre ölçümündeki hatayı belirli oranda tolere edebilmekle birlikte farklı bir motor için en azından yeni bir parametre ölçüm süreci gerektirecektir. Bunun yanında motorun çalışma koşullarının parametreler üzerindeki etkisi göz önüne alındığında, motor parametrelerinin değişmesiyle akım gözlemleyici model ile motor arasındaki modelleme hatası artacaktır. Ayrıca pratikte denetim sisteminde yer alması zorunlu olan eviricinin akım gözlemleyici modelde yer almaması nedene ile de modelleme hatası oluşacaktır. Bu durumda motor parametrelerindeki değişimin modele yansitılması için ek olarak parametre uyarlama algoritması gerektirebilir. Kaynak [26,27]'de, motor modelinden yararlanarak oluşturulan akım gözlemleyici modeli ile algılayıcısız denetimin başarısı, rotor direnci küçük sınırlar arasında değiştirilerek incelenmiş ve motora yük momenti uygulanması durumda meydana gelen sürekli durum hatası gösterilmiştir.

Akım gözlemleyicili algılayıcısız denetim yönteminin akı ve hız tahmini gerektirmemesi önemli bir avantajını oluştururken motor parametrelerine duyarlı olması da önemli bir sakıncasını oluşturmaktadır. Bu nedenle, akım gözlemleyicinin motor parametrelerinden bağımsız ve dayanıklı hale getirilmesi yöntemin başarısını artıracaktır. $\mathrm{Bu}$ amaçla, bu çalışmada akım gözlemleyici olarak SBA kullanılarak motor parametrelerinden bağımsız bir gözlemleyici elde edilmiştir. Önerilen SBA akım gözlemleyici ile birlikte dolaylı vektrö denetimli asenkron motorun hız denetim sisteminin blok diyagramı Şekil 3'de verilmiștir. Önerilen SBA'nın parametreleri gerçek zamanlı olarak uyarlandığı için, motor parametrelerindeki değişimler motor akım ve gerilimleri vasıtası ile SBA'ya aktarılmaktadır. Şekilden görüldüğü gibi motorun dq akımları için ayrı ayrı SBA akım gözlemleyicisi kullanılmış ve böylece SBA'nın hesaplama yükü de hafifletilmiştir. Çünkü SBA' daki üyelik fonksiyonlarının sayısı, girişlerin sayısına göre artan üstel bir ilişkidir.

Dolaylı vektör denetim yapısında, çok düşük hızlarda bile çok iyi sonuçlar elde edilebildiğinden asenkron motorların yüksek başarımlı uygulamalarında daha çok dolaylı vektör denetim yöntemi ve kompanzasyon işlemlerine gereksinim duymadan alan yönlendirmesinin sağlanabildiği rotor alan yönlendirmesi tercih edilmektedir. Denklem 18 kullanılarak referans açısal kayma hızı $\left(\omega_{s l}^{*}\right)$,

$$
\omega_{s l}^{*}=\frac{R_{r}}{L_{r}} \frac{i_{q s}^{e^{*}}}{i_{d s}^{e^{*}}}
$$

olarak yazılabilir. Burada $i_{q s}^{e^{*}}$ - hız denetleyiciden elde edilen referans moment akım bileşeni, $i_{d s}^{e^{*}}-$ stator akımının referans akı bileşenidir. Anma akımlarının altındaki hız denetimleri için $i_{d s}^{e^{*}}$ akımı, anma değerinde sabit olarak alınabilir. Motor hızının ( $\omega)$ ölçüldüğünü kabul edersek vektör dönüşümü için gerekli referans açısal hız $\left(\omega_{e}^{*}\right)$,

$$
\omega_{e}^{*}=\omega_{s l}^{*}+\frac{p}{2} \omega
$$


ve referans vektör açısı ise aşağıdaki gibi olur.

$$
\theta_{\mathrm{e}}^{*}=\int \omega_{\mathrm{e}}^{*} \mathrm{dt}
$$

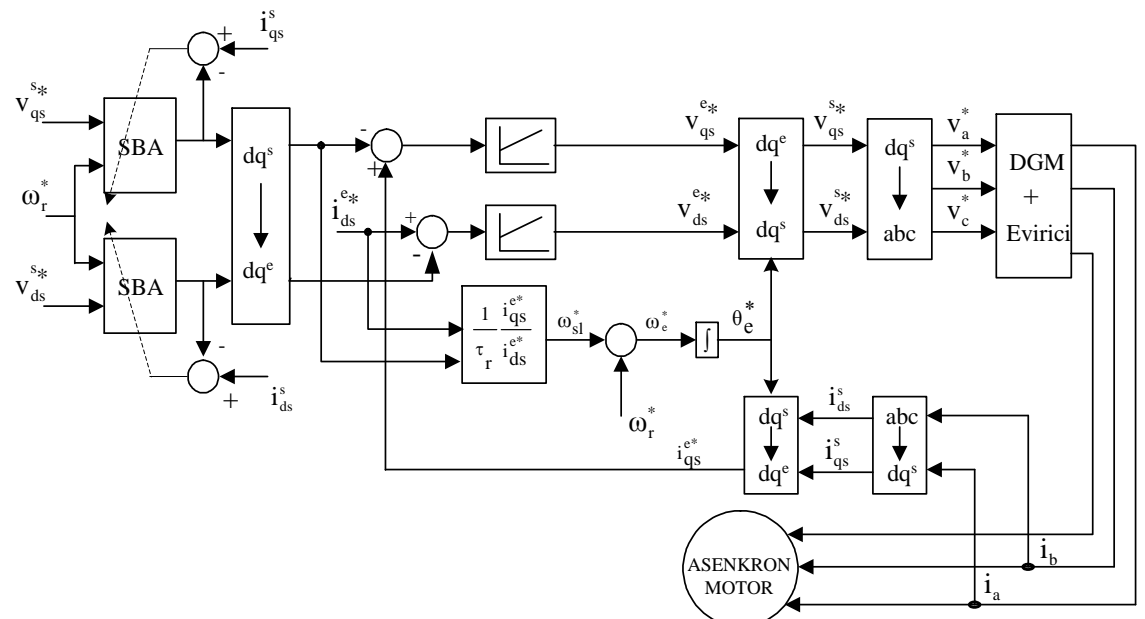

Şekil 3. Sinirsel bulanık akım gözlemleyici ile ASM'nin algılayıcısız hız denetimi

\subsection{Sugeno Tipi Akım Gözlemleyici SBA}

ASM'nin algılayıcısız hız denetiminde kullanılan, iki giriş tek çıkışlı ve her bir giriş için üç üyelik fonksiyonunun seçildiği Sugeno tipi SBA yapısı Şekil 4'de verilmiştir. Bu çalışmada kullanılan Sugeno tipi SBA iki adet kullanılmıştır ve giriş değişkenleri, referans hız ve motor referans gerilimleri olarak alınmıştır. SBA'lardan birine, duran referans çatı $q$ ekseni gerilimi giriş olarak uygulanırken çıkışı iqsm ve diğerine duran referans çatı $d$ ekseni gerilimi giriş olarak uygulanırken çıkışı $i_{d s m}$ olarak seçilmiştir.

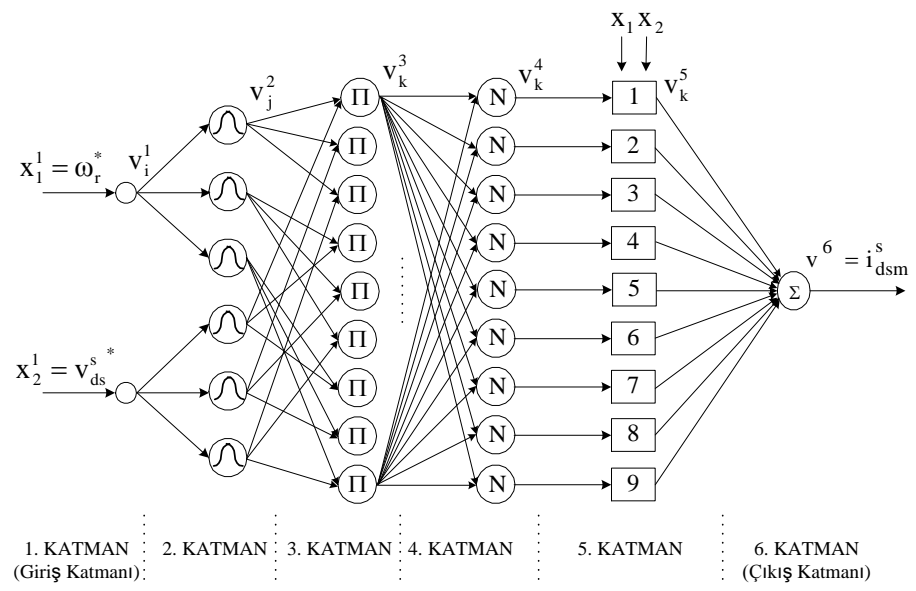

Şekil 4. İki girişli tek çıkışlı Sugeno tip SBA yapısı

Bu durumda akım gözlemleyici SBA’ 'n girişleri,

$$
x_{1}=\omega_{r}^{*}(t)^{\prime} \quad x_{2}=v_{d s}^{s^{*}}
$$

ve giriş katmanın çıkışları,

$$
u_{i}^{1}=x_{i}^{1}, \quad v_{i}^{1}=f_{i}^{1}\left(u_{i}^{1}\right)=x_{i}^{1}
$$

olarak yazılabilir. İkinci katman üyelik fonksiyonları katmanıdır. Her bir giriş için üçer adet üyelik fonksiyonu belirlenmiş ve üyelik fonksiyonları genelleştirilmiş bell fonksiyonu alınmıştır. 


$$
u_{j}^{2}=\left|\frac{x_{i}^{2}-m_{i j}}{\sigma_{i j}}\right|^{2 b_{i}}, \quad v_{j}^{2}=f_{j}^{2}\left(u_{j}^{2}\right)=\frac{1}{1+u_{j}^{2}},\{\mathrm{j}=2\}
$$

Burada $\sigma_{i j}, m_{i j}$ ve $b_{i}$ üyelik fonksiyonlarının uyarlanacak parametreleridir ve giriş parametreleri olarak da adlandırılır. $x_{i}^{2}$, 2. katmanın i. hücresinin girişidir. Kural tabanının oluşturulduğu üçüncü katman П sembolüyle gösterilen düğ̈̈mlerden oluşmuştur ve her düğüm kendine gelen işaretlerin çarpımını çıkışına verir. Burada VE bulanık işlemi gerçekleştirilmekle birlikte diğer T-norm işlemleri de kullanılabilir. VE bulanık işleminin gerçekleştirilmesiyle k. hücrenin çıkışı,

$$
u_{k}^{3}=\prod_{j} x_{j}^{3}, \quad v_{k}^{3}=f_{k}^{3}\left(u_{k}^{3}\right)=u_{k}^{3}
$$

olarak yazılır. Burada $x_{j}^{3}$, 3. katmanın j. hücresinin girişidir. Dördüncü katmandaki her bir hücre $\mathrm{N}$ ile gösterilmiştir ve her bir hücre, bir kuralın normalleştirilmiş ateşleme kuvvetini hesaplar. m. düğüm çıkışı, m. kuralın ateşleme derecesinin bütün kuralların ateşleme derecelerinin toplamına oranından aşağıdaki gibi hesaplanır.

$$
u_{k}^{4}=\sum_{k} x_{k}^{4}, \quad v_{k}^{4}=f_{k}^{4}\left(u_{k}^{4}\right)=\frac{x_{k}^{4}}{u_{k}^{4}}
$$

$x_{k}^{4}$, 4. katmanın k. hücresinin girişidir. Beşinci katmandaki her bir n düğümünde, ağırlıklandırılmış $v_{k}^{4}\left(p x_{1}+q x_{2}+r\right)$ sonuç değeri hesaplanır. Burada $v_{k}^{4} 4$. katmanın çıkışı, $\{\mathrm{p}, \mathrm{q}, \mathrm{r}\}$ ise uyarlanacak parametre kümesidir. Bu katmandaki parametreler sonuç parametreleri olarak adlandırılırlar.

$$
u_{k}^{5}=x_{k}^{5}, \quad v_{k}^{5}=f_{o}^{6}\left(u_{o}^{6}\right)=u_{k}^{5} g_{k}=u_{k}^{5}\left(p_{k} x_{1}^{1}+q_{k} x_{2}^{1}+r_{k}\right)
$$

$x_{k}^{5}$, 5. katmanın k. hücresinin girişidir. Altıncı katmanda $\sum$ sembolüyle gösterilen tek bir dügüm vardır ve girişine gelen işaretlerin toplamını çıkışına verir.

$$
u_{o}^{6}=\sum_{k} x_{k}^{6}, \quad v_{o}^{6}=i_{d s m}^{s} * f_{o}^{6}\left(u_{o}^{6}\right)=u_{o}^{6}
$$

\subsection{Sugeno Tipi Akım Gözlemleyici SBA}

Bir SBA, BM işlevlerini YSA ile gerçekleştirerek, YSA'nın öğrenme ve uyarlama yeteneğini kazanır. Böylece SBA'nın tasarımında, BM'nin tasarımında karşılaşılan üyelik fonksiyonlarının şeklinin belirlenmesi ve kural tabanının oluşturulması gibi zorluklar, YSA tarafından kazandırılan öğrenme ve uyarlama yeteneği ile aşlabilir. Bu nedenle SBA'nın da tıpkı YSA gibi çeşitli öğrenme algoritmaları ile eğitilerek parametrelerinin uyarlanması gereklidir. Literatürde SBA için pek çok öğrenme algoritması önerilmekle birlikte, uygulamada daha çok geriye yayılım algoritması veya geriye yayılım algoritması ile en küçük kareler yönteminin birlikte kullanıldığı melez öğrenme yöntemleri kullanılır. Melez öğrenme yönteminde çıkış parametreleri doğrusal bir fonksiyonun parametreleri olması nedeniyle en küçük kareler yöntemine göre belirlenirken, giriş parametreleri geriye yayılım algoritmasıyla belirlenir. Ancak en küçük kareler yöntemi gerçek zamanlı uygulamalarda gerçekleştirilemediğinden, genelde çıkış parametrelerinin de geriye yayılımla uyarlanması tercih edilmektedir. Geriye yayılım algoritması ile örneksel öğrenme yöntemi kullanılarak giriş ve çıkış parametrelerinin güncellenmesi için, izleme hatası (e) minimize edilecek karesel hata (E) aşağıdaki gibi belirlenir.

$$
e(k)=i_{d s}^{s}(t)-i_{d s m}^{s}(t), \quad E=\frac{1}{2} e^{2}(t)
$$


SBA'nın uyarlanacak herhangi bir giriş ve çıkış parametresi $\varphi$ olarak alınırsa, geriye yayılım algoritmasını kullanarak herhangi bir $\varphi$ parametresinin güncellenmesi,

$$
\varphi(k)=\varphi(k-1)+\Delta \varphi(k)=\varphi(k-1)+\left(-\alpha \frac{\partial E(k)}{\partial \varphi(k)}\right)
$$

olarak bulunur. Burada $\alpha$-öğrenme oranıdır ve $\frac{\partial E}{\partial \varphi}$ kısmi türevinin elde edilebilmesi için, E fonksiyonundan ilgili parametreye kadar kısmi türev zinciri kullanılır. Buna göre sonuç parametreleri aşağıdaki gibi güncellenebilir.

$$
\frac{\partial E}{\partial p_{k}}=\delta^{1} \frac{\partial v^{6}}{\partial u^{6}} \frac{\partial u^{6}}{\partial v_{k}^{5}} \frac{\partial v_{k}^{5}}{\partial p_{k}}=\delta^{1} u_{k}^{5} x_{1}^{1}=\delta^{1} \frac{x_{k}^{4}}{\sum_{k} x_{k}^{4}} x_{1}^{1}
$$

Burada $\delta^{l}$-yöresel gradyandır.

$$
\delta^{1}=\frac{\partial E}{\partial e} \frac{\partial e}{\partial i_{d s m}^{s}} \frac{\partial i_{d s m}^{s}}{\partial v^{6}}
$$

Benzer şekilde SBA'nın önkoşul parametreleri de güncellenebilir. Genelleştirilmiş bell fonksiyonu için $\sigma$ önkoşul parametresinin güncellemesi aşağıda verilmiştir.

$$
\frac{\partial E}{\partial \sigma_{i, 2}}=\delta^{1} \frac{\partial v^{6}}{\partial u^{6}} \frac{\partial u^{6}}{\partial v_{k}^{5}} \frac{\partial v_{k}^{5}}{\partial u_{k}^{5}} \frac{\partial u_{k}^{5}}{\partial v_{k}^{4}} \frac{\partial v_{k}^{4}}{\partial u_{k}^{4}} \frac{\partial u_{k}^{4}}{\partial v_{k}^{3}} \frac{\partial v_{k}^{3}}{\partial u_{k}^{3}} \frac{\partial u_{k}^{3}}{\partial v_{j}^{2}} \frac{\partial v_{j}^{2}}{\partial \sigma_{i, 2}}=\delta^{1} g_{k} \frac{\sum_{k} x_{k}^{4}-x_{k}^{4}}{\left(\sum_{k} x_{k}^{4}\right)^{2}} \prod_{j} x_{j}^{3}\left(\frac{2 b_{i}}{x_{i}^{1}-m_{i, 2}}\right) v_{j}^{2}\left(1-v_{j}^{2}\right)
$$

\section{Algılayıcısız Denetim Sisteminin SIII ile Gerçeklemesi}

SBA akım gözlemleyicili algılayıcısız denetim sisteminin Şekil 3'te verilen diyagramın deneysel gerçeklemesi Şekil 5'te verilmiştir. SBA ile algılayıcısız denetim algoritmasının gerçekleştirilmesi ve gerçek zamanlı eğitimi, vektör dönüşümleri ve evirici için gerekli anahtarlama işaretlerinin elde edilmesi oldukça yoğun hesaplamalar gerektirmektedir. Ayrıca, eviricinin anahtarlama frekansının yeterince yüksek tutulması da iyi bir vektör denetimi için gereklidir. Bu nedenle, SBA'nın kullanıldığı denetim sistemlerinin gerçekleştirilmesi, hızlı ve işlem yetenekleri güçlü SİI gerektirir. Bu çalışmada, dSPACE firmasının DS1104 denetleyici kartı kullanılmıştır.

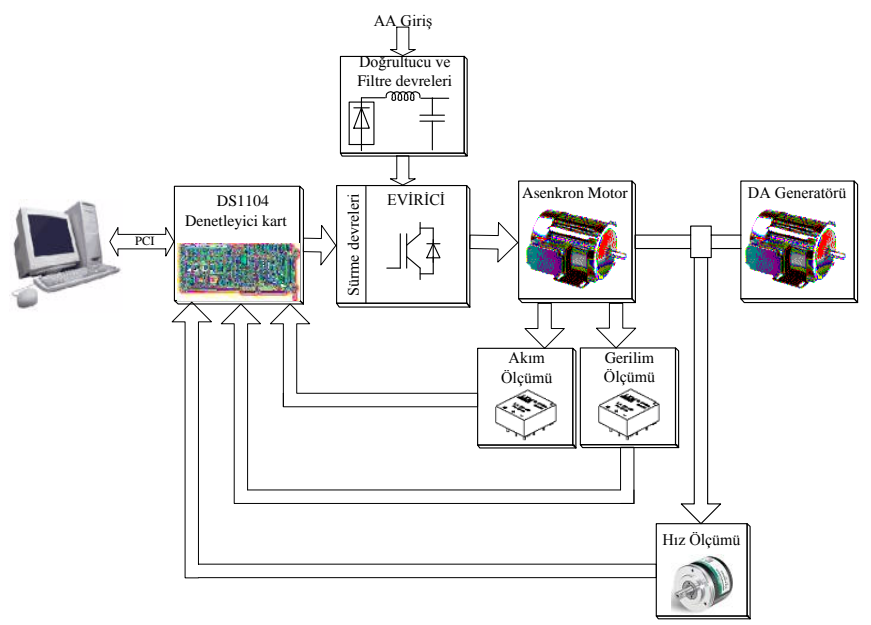

Şekil 5. Deney düzeneğinin blok diyagramı 
Deney düzeneğine ait Şekil 5'te görülen motorun gerçek hız bilgisi, algılayıcısız denetim algoritmasında kullanılmamaktadır ve sadece referans hız ile karşılaştırmak maksadı ile ölçülmüştür. Motordan ölçülen konum bilgisi DS1104 denetleyici kartının sayısal girişlerine, akım bilgileri ise kartın ADC girişlerine uygulanmaktadır. Denetleyici kart, asenkron motorun algılayıcısız denetim algoritmasını gerçek zamanlı olarak işleyerek evirici devresinin anahtarlama işaretleri üretir. DS1104 denetleyici kartının sayısal çıkışlarında bu işaretler alınarak evirici devresine uygulanır ve böylece motorun istenilen hızda dönebilmesi için üretilen anahtarlama işaretlerine göre elde edilen üç faz gerilimleri motora uygulanır.

Matlab/Simulink uyumlu DS1 104 denetleyici kartı ile algılayıcısız denetimin deneysel gerçekleştirilmesi için hazırlanan Simulink model dosyası Şekil 6’da verilmiştir.

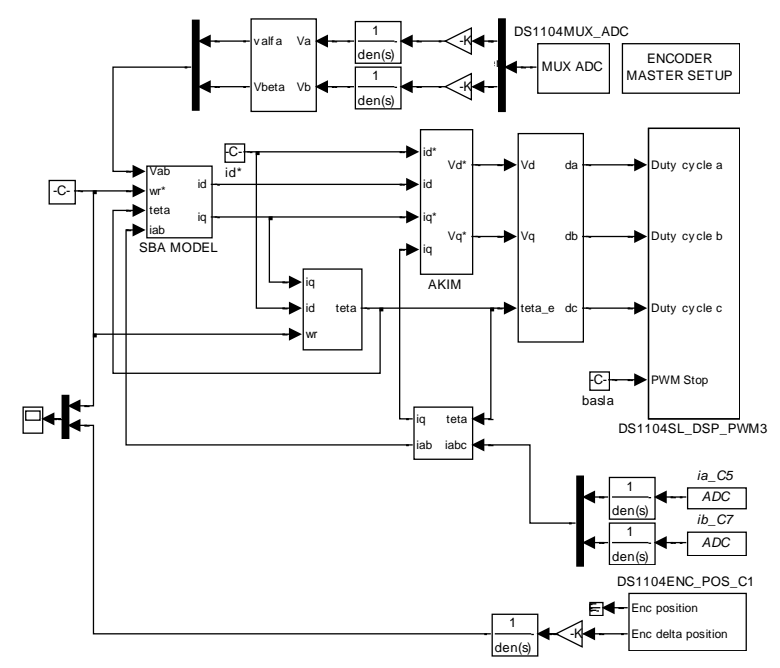

Şekil 6. DS1104 ile deneysel çalışma için MATLAB/Simulikte oluşturulan denetim algoritması

Denetim yapısında örnekleme zamanı $2 \mathrm{~ms}$ ve eviricinin anahtarlama frekansı $5 \mathrm{kHz}$ olarak seçilmiştir. Motor milinin açısal konumu bir mil kodlayıcı ile algılanarak denetleyici kartın sayısal girişlerine uygulanır. Sayısal girişlere uygulanan bu bilgiler enkoder blokları yardımı ile açısal hız bilgisine dönüştürülür ve köşe frekansı $100 \mathrm{~Hz}$ olan sayısal bir alçak geçiren filtreden geçirilerek arzu edilen açısal hız ile karşılaştırılmak üzere çoklayıcı girişine uygulanır. Mil kodlayıcı ile ölçülen hız, sistemde herhangi bir geri besleme amacı ile kullanılmaz. Hız denetimi anma hızının altında gerçekleştirildiğinden referans d-eksen akımı sabit olarak seçilmiştir.

Simulinkte oluşturulan model dosyası derlenerek Sï'ye yüklenir. Şekil 7'de verilen ControlDesk Developper yazılımı ile hazırlanan arayüz sayesinde denetim yapısındaki bütün işaretler gerçek zamanlı olarak izlenebilir ve denetim yapısındaki parametreler gerçek zamanlı olarak değiştirilebilir.

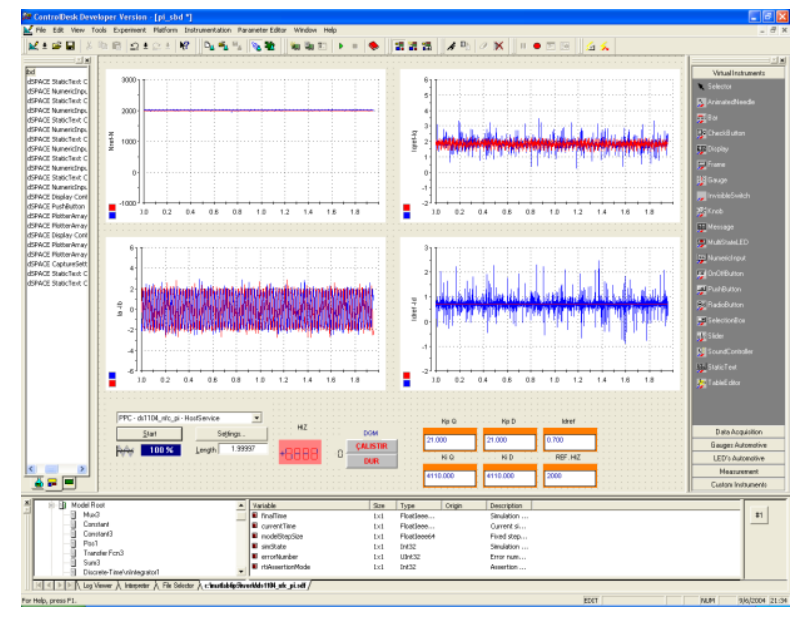

Şekil 7. Oluşturulan ara yüzün görünümü 


\section{Benzetim ve Deneysel Sonuçlar}

Asenkron motorların akım gözlemleyicili algılayıcısız hız denetim performansı, sabit parametreli model ile SBA model kullanılarak benzetim ve deneysel çalışmalarla test edilmiştir. Benzetim ve deneysel çalışmalarda akım gözlemleyici olarak kullanılan SBA'nın ön koşul parametreleri eğitilmemiş, sonuç parametreleri ise gerçek zamanlı olarak geriye yayılım öğrenme algoritması ile eğitilmiştir.

SBA ve sabit parametreli akım gözlemleyicili algılayıcısız denetimden elde edilen benzetim sonuçları 2000 d/dak. referans hız için Şekil 8'de verilmiştir. Şekil 8(a)' da SBA ile Şekil 8(b) de ise sabit parametreli model ile algılayıcısız denetimin hız izleme performansı verilmiştir. Şekil 8(c)' ve (d) de ise tork akımlarının $\left(i_{q s}^{e^{*}}\right.$ ve $\left.i_{q s}^{e}\right)$ değişimi verilmiştir. Şekil 8' den, sabit parametreli model ile motor modeli aynı parametreler sahip olduğundan benzetim sonucunun SBA ile denetim kadar tatmin edici olduğu görülmektedir.

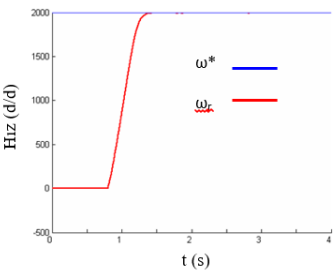

(a)

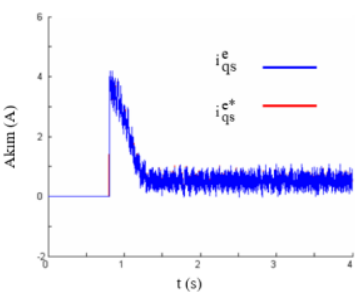

(c)

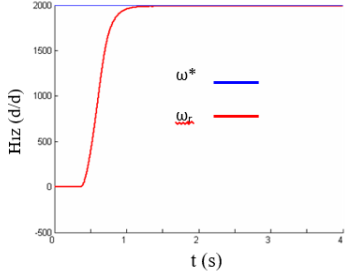

(b)

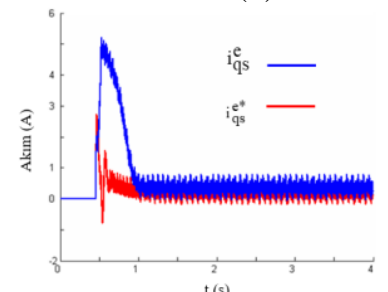

(d)

Şekil 8. 2000d/d referans hızda her iki modelden elde edilen benzetim sonuçları, (a) SBA'lı model için referans hızın ve motor hızının değişimi, (b) Motor denklem modeli için referans hızın ve motor hızının değişimi, (c)

SBA için $i_{q s}^{e^{*}}$ ve $i_{q s}^{e}$ akımlarının değişsimi, (d) Dinamik model için $i_{q s}^{e^{*}}$ ve $i_{q s}^{e}$ akımlarının değişimi

Düşük hızlarda da (250 d/d) SBA ve sabit parametreli model ile algılayıcısız denetimden iyi bir denetim performansının elde edildiği Şekil 9'da verilen benzetim sonucundan görülmektedir.

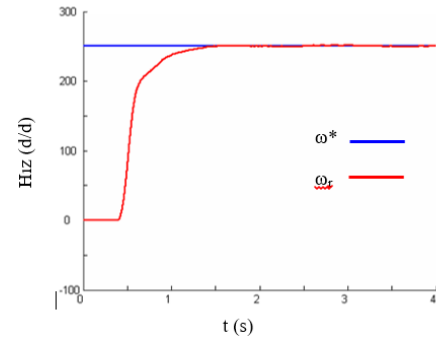

(a)

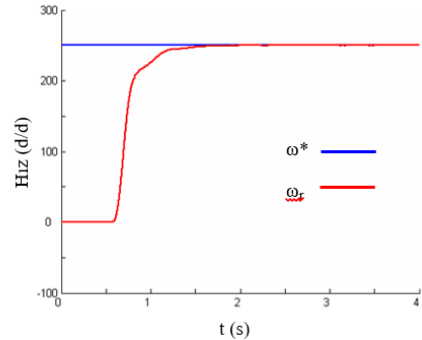

(b)

Şekil 9. (a) $250 \mathrm{~d} / \mathrm{d}$ basamak referans hız için SBA akım gözlemleyicili sistemin hız izleme performansı, (b) 250 $\mathrm{d} / \mathrm{d}$ basamak referans hız için sabit parametreli model ile hız izleme performansı

Şekil 10'da, düşük hız referansında (500 d/d) SBA ve sabit parametreli algılayıcısız denetimin deneysel performansı verilmiştir. Deneysel çalışmada, motor modelinden belirlenen akım gözlemleyicinin parametreleri, motorun gerçek parametreleri ile aynı olmadığından sabit parametreli algılayıcısız denetimin performansında bozulmalar görülmektedir. 


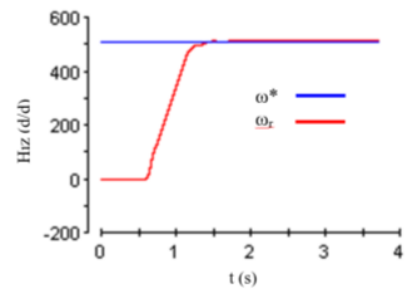

(a)

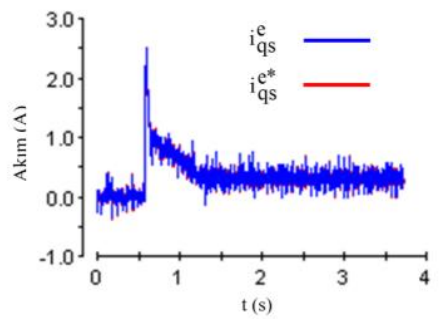

(c)

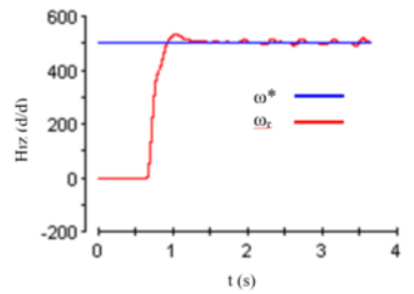

(b)

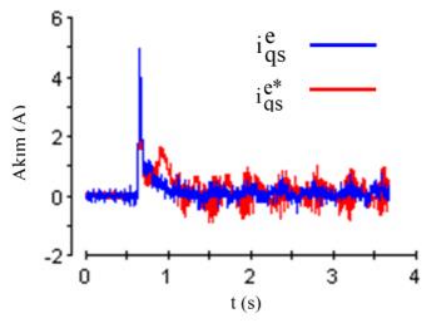

(d)

Şekil 10. Motor yüksüz iken 500d/d referans hızda her iki modelden elde edilen deneysel sonuçlar, (a) SBA'lı model için referans hızın ve motor hızının değişimi, (b) Motor denklem modeli için referans hızın ve motor hızının değişimi, (c) SBA için $i_{q s}^{e^{*}}$ ve $i_{q s}^{e}$ akımlarının değişimi, (d) Dinamik model için $i_{q s}^{e^{*}}$ ve $i_{q s}^{e}$ akımlarının değişimi

Şekil 11'de, yüksek hızlarda (2000 d/d) ve motor yüklü durumda iken SBA ve sabit parametreli algılayıcısız denetimden elde edilen deneysel hız izleme performansı verilmiştir. SBA ile denetimin performansı tatmin edici iken sabit parametreli denetim sisteminde motor yüküne de bağlı olarak kalıcı durum hatası görülmektedir.

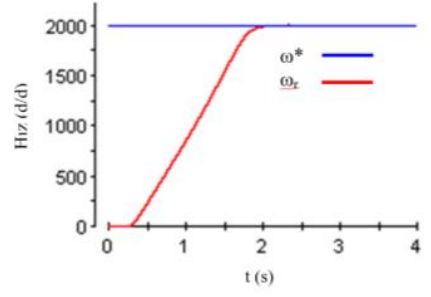

(a)

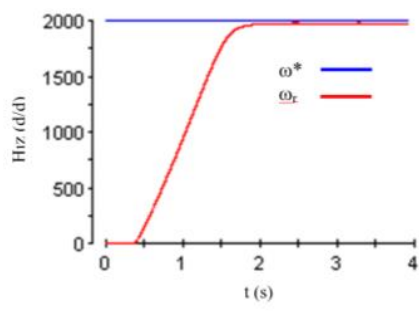

(b)

Şekil 11. Motor yüklü iken $2000 d / d$ referans hızda her iki modelden elde edilen deneysel sonuçlar, (a) SBA'lı model için referans hızın ve motor hızının değişimi, (b) Motor denklem modeli için referans hızın ve motor hızının değişimi.

\section{Sonuç}

Bu çalışmada, motorun dinamik modeline göre tasarlanan sabit parametreli akım gözlemleyici ve SBA akım gözlemleyici kullanılarak, vektör denetimli bir ASM'nin algılayıcısız hız denetimi gerçekleştirilmiştir. Denetim algoritması MATLAB/Simulink ile programlanmış ve dSPACE DS1104 denetleyici kart ile gerçekleştirilmiştir. Deneysel sonuçlar, değişkenlere gerçek zamanlı ulaşmayı sağlayabilen ve denetleyici kart için hazırlanan ControlDesk Developper yazılım ile oluşturulan arayüz sayesinde doğrudan elektronik ortamda elde edilmiştir. Akım gözlemleyici SBA modelinin sonuç parametreleri gerçek zamanlı ve örneksel olarak geriye yayılım öğrenme algoritması ile eğitilmiştir. Algılayıcısız denetim yöntemlerine göre farklı bir yaklaşım sunan akım gözlemleyicili algılayıcısız denetimde, sabit parametreli model yerine SBA kullanılarak algılayıcısız denetimin başarımının iyileştiği deneysel sonuçlarla gösterilmiştir. Bu bölümde, çalışmanın amacı ve dikkat çekici sonuçları somut bir şekilde kısaca verilmelidir ayrıca çalışmanın sonuçları ile ilgili okuyuculara iletilmesi istenen öneri ve görüşler belirtilebilir. 


\section{Kaynaklar}

[1] Kojabadi HM, Chang L, Doriaswami R. Recent progress in sensorless vector controlled induction motor drives. 2002 Large Engineering Systems Conference on Power Engineering; June 2002; 80-85.

[2] Kim YR, Sul SK, Park MH. Speed Sensorless Vector Control of Induction Motor Using Extended Kalman Filter. IEEE Trans. Ind. Appl. 1994; 30 (5): 1225-1233.

[3] Du T, Vas P, Stronach F. Design and Application of Extended Observers for Joint State and Parameter Estimation in HighPerformance AC Drives. IEE Proc. Electr. Power Appl. 1995; 142 (2): 71-77.

[4] Al-Tayie J, Acamley P. Estimation of Speed Stator Temperature and Rotor Temperature in Cage Induction Motor Drive Using Extended Kalman Filter Algorithm. Proc. IEE-Elec. Power Appl. 1997; 144: 301-309.

[5] Schauder C, Adaptive Speed Identification for Vector Control of Induction Motors without Rotational Transducers. IEEE Trans. Indus. Appl. 1992; 28: 1054-1061.

[6] Lin YN, Chen CL. Adaptive Pseudoreduced-Order Flux Observe for Speed Sensorless Field Oriented Control of IM. IEEE Trans. Ind. Electron. 1999; 46: 1042-1045.

[7] Yang G, Chin TH, Adaptive-Speed Identification Scheme for Vector-Controlled Speed Sensorless Inverter-Induction Motor Drive. IEEE Trans. Ind. Appl. 1993; 29 (4): 820-825.

[8] Peng FZ, Fukao T. Robust Speed Identification for Speed Sensorless Vector Control of Induction Motors. IEEE Trans. Ind. Appl. 1994; 30 (5): 1234-1240.

[9] Kojabadi HM, Chang L. Model Reference Adaptive System Pseudoreduced-Order Flux Observer for Very Low-Speed and Zero-Speed Estimation in Sensorless Induction Motor Drives. in Proc. of Power Elec. Specialist Conf. PESC; 2002: 301-305.

[10] Derdiyok A. Speed-sensorless control of induction motor using a continuous control approach of sliding-mode and flux observer. IEEE Transactions on Industrial Electronics 2005; 52 (4): 1170-1176.

[11] Reman H, Derdiyok A, Güven M K. A New Current Model Flux Observer for Wide Speed Range Sensorless Control of an Induction Machine. IEEE Trans. Power Elec. 2002; 17 (6): 1041-1048.

[12] Ben-Brahim L. Motor Speed Identification via Neural Networks. Industry Applications Magazine, IEEE. 1995; 1: 28 -32.

[13] Xianmin M, Zhi N. Neural Network Speed Identification Scheme for speed Sensor-less DTC Induction Motor Drive System. Power Electronics and Motion Control Conference; 2000; 1242-1245.

[14] Ben-Brahim L, Tadakuma S. Speed Control of Induction Motor without Rotational Transducers. Industry Applications Conference, IEEE; 1998; 625-632.

[15] Cirrincione M, Pucci M. An MRAS Based Speed Estimation Method with a Linear Neuron for High Performance Induction Motor Drives and Its Experimentation. Electric Machines and Drives Conference, IEMDC'03, IEEE; 2003; 617-623.

[16] Karanayil B, Rahman MF, Grantham C. Speed Sensorless Vector Controlled Induction Motor Drive with Rotor Time Constant Identification Using Artificial Neural Networks. Proceedings of the 2002 IEEE International Symposium; 2002; 715-720.

[17] Kim SH, Park TS, Yoo JY, Park GT. Speed-Sensorless Vector Control of an Induction Motor Using Neural Network Speed Estimation. IEEE Transactions on Industrial Electronics 2001; 48: 609-614.

[18] Orlowska-Kowalska T, Kowalski CT. Neural Network Application for Flux and Speed Estimation in the Sensorless Induction Motor Drive. Proceedings of the IEEE International Symposium on Industrial Electronics; 1997; 1253-1258.

[19] Lu HC, Hung TH, Tsai CH. Sensorless Vector Control of Indcution Motor Using Artificial Neural Network. ISCAS 2000IEEE Int. Sym. On Circuits and Systems Geneva; 2000; Switzerland. 489-492.

[20] Jalili K, Farhangi S, Iranizad ES. Sensorless Vector Control of Induction Motors in Fuel Cell Vehicle Using a NeuroFuzzy Speed Controller and an On-Line Artificial Neural Network Speed Estimator. Proc. IEEE Int. Conf. Control Appl.; 2001; 259-264.

[21] Leksono E, Prihatin R, Kadiman K. Fuzzy Auto Reset Controller for Speed Sensorless Induction Motor Drive. Industrial Electronics Society 26th Annual Conference of the IEEE; 2000; 2321-2326.

[22] Campbell J, Summer M. Practical Sensorless Induction Motor Drive Employing an Artificial Neural Network for Online Parameter Adaptation. IEE Proc-Elect. Power Appl. 2002; 149 (4): 255-260.

[23] Montanari M, Peresada SM, Rossi C, Tilli A. Speed sensorless control of induction motors based on a reduced-order adaptive observer. IEEE Transactions On Control Systems Technology 2007; 15 (6): 1049-1064.

[24] Purwanto E, Arifin S, Bian-Sioe S. Application of Adaptive Neuro Fuzzy Inference System on the Development of the Observer for Speed Sensorless Induction Motor. Electrical and Electronic Technology 10 International Conference; 2001; 409-414.

[25] Zhang J, Morris A J. Fuzzy Neural Networks for Nonlinear Systems Modeling. Proc. Inst. Elect. Eng. Contr. Theory Appl. 1995; 142: 551-556.

[26] Kwon YA, Kim SH. A New Scheme for Speed-Sensorless Control of Indcution Motor. IEEE Trans. Ind. Elect. 2004; 51 (3): 545-550.

[27] Kwon YA, Kim SH, Oh SH, Speed Sensorless Control of Induction Motor by Current Error Compensation. IECON Control and Enst. Conf.; 1997; 966-970. 